\title{
PENENTUAN NILAI RESISTIVITAS UNCONSOLIDATED SAND PADA LOW MOISTURE CONTENT MENGGUNAKAN MIKROAMPERMETER PADA ALIRAN SUNGAI KRASAK, SLEMAN, DAERAH ISTIMEWA YOGYAKARTA
}

\author{
Ajimas Pascaning Setiahadiwibowo ${ }^{1 *}$, Ocky Bayu Nugroho $^{2}$, Yudha Agung Pratama ${ }^{1}$ \\ ${ }^{1}$ Teknik Geofisika UPN Veteran Yogyakarta. Indonesia \\ ${ }^{2}$ Teknik Geologi UPN Veteran Yogyakarta, Indonesia \\ *Corresponding author. Email: ajimas@upnyk.ac.id
}

Manuscript received: 11 February 2020; Received in revised form: 21 April 2020; Accepted: 23 April 2020

\begin{abstract}
Abstrak.
Uji resistivitas unconsolidated sand pada low moisture content menggunakan peralatan dengan resolusi mikroampermeter. Nilai resistivitas pada penelitian ini dipengaruhi oleh banyaknya air yang terdapat pada endapan pasir. Penelitian ini dilakukan dengan mengambil 3 conto yang tersebar pada endapan Sungai Krasak, Kabupaten Sleman. Nilai resistivitas pada penelitian ini diperoleh dari conto yang dikeringkan kemudian ditambahkan air secara bertahap ( $3 \mathrm{ml})$. Berdasarkan hasil penelitian ini maka nilai resistivitas endapan pasir lepas di Sungai Krasak berkisar antara 23,31 $\Omega \mathrm{m}-1086,302$ $\Omega \mathrm{m}$, semakin jauh dari batuan sumber maka sebaran variasi nilai resistivitas lebih bervariasi dan semakin tinggi moisture content maka nilai resistivitas semakin rendah.
\end{abstract}

Kata kunci: Moisture Content; Resistivitas; Sungai Krasak; Unconsolidate Sand.

\begin{abstract}
Unconsolidated sand resistivity test on low moisture content using equipment with micro amperemeter resolution. The resistivity in this study is influenced by the amount of water contained in the sand deposit. This research was carried out by taking 3 samples that were scattered in the Krasak River sediment, Sleman Regency. The resistivity value in this study was obtained from the dried sample and then added water gradually $(3 \mathrm{ml})$. Based on the results of this study, the resistivity of loose sand deposits in the Krasak River ranged from $23.31 \Omega \mathrm{m}-1086.302 \Omega \mathrm{m}$, the farther away from the source rocks the distribution of resistive values varied more varied and the higher of moisture content the lower the resistivity.
\end{abstract}

Keywords: Krasak River; moisture content; resistivity; unconsolidate sand.

\section{Pendahuluan}

Survei geolistrik bersentuhan langsung dengan soil di permukaan. Soil di permukaan memiliki peran besar terhadap model penjalaran arus yang ideal ke dalam bumi. Pemahaman yang lebih terhadap sifat fisik soil ini akan membantu dalam kegiatan studi geolistrik.
Adanya kandungan mineral baik mineral yang konduktif atau nonkonduktif dengan berbagai nilai porositas akan mempengaruhi nilai resistivitas yang disebabkan oleh adanya saturasi air pada pori (Rahman dkk., 2016). Resistivitas dari massa batuan di bawah permukaan air bergantung pada porositas, resistivitas air tanah dan kandungan lempung. Di antara faktor - faktor ini, resistivitas air tanah 
hampir konstan untuk jenis batuan yang sama. Oleh karena itu, resistivitas massa batuan sangat kuat dipengaruhi oleh porositas yang terkait dengan retakan dan patahan, dan kandungan lempung terkait dengan pelapukan dan fenomena geologis lainnya (Matsui, 2000).

Gunung Merapi merupakan gunungapi tipe basalt-andesitik dengan komposisi $\mathrm{SiO}^{2}$ berkisar antara $50-58 \%$. Beberapa lava yang bersifat lebih basa mempunyai $\mathrm{SiO}^{2}$ yang lebih rendah sampai sekitar $48 \%$.
Batuan Merapi tersusun dari plagiolklas, olivin, piroksen, magnetit dan ampibol. Plagioklas merupakan mineral utama pada batuan Merapi dengan komposisi sekitar 34\% (van Bemmelen, 1949).

Secara administratif daerah penelitian termasuk dalam Kabupaten Sleman, Yogyakarta yang berada pada daerah aliran sungai besar. Daerah sungai tersebut termasuk dalam sungai yang mengendapkan material vulkanik Gunung Merapi (Gambar 1).

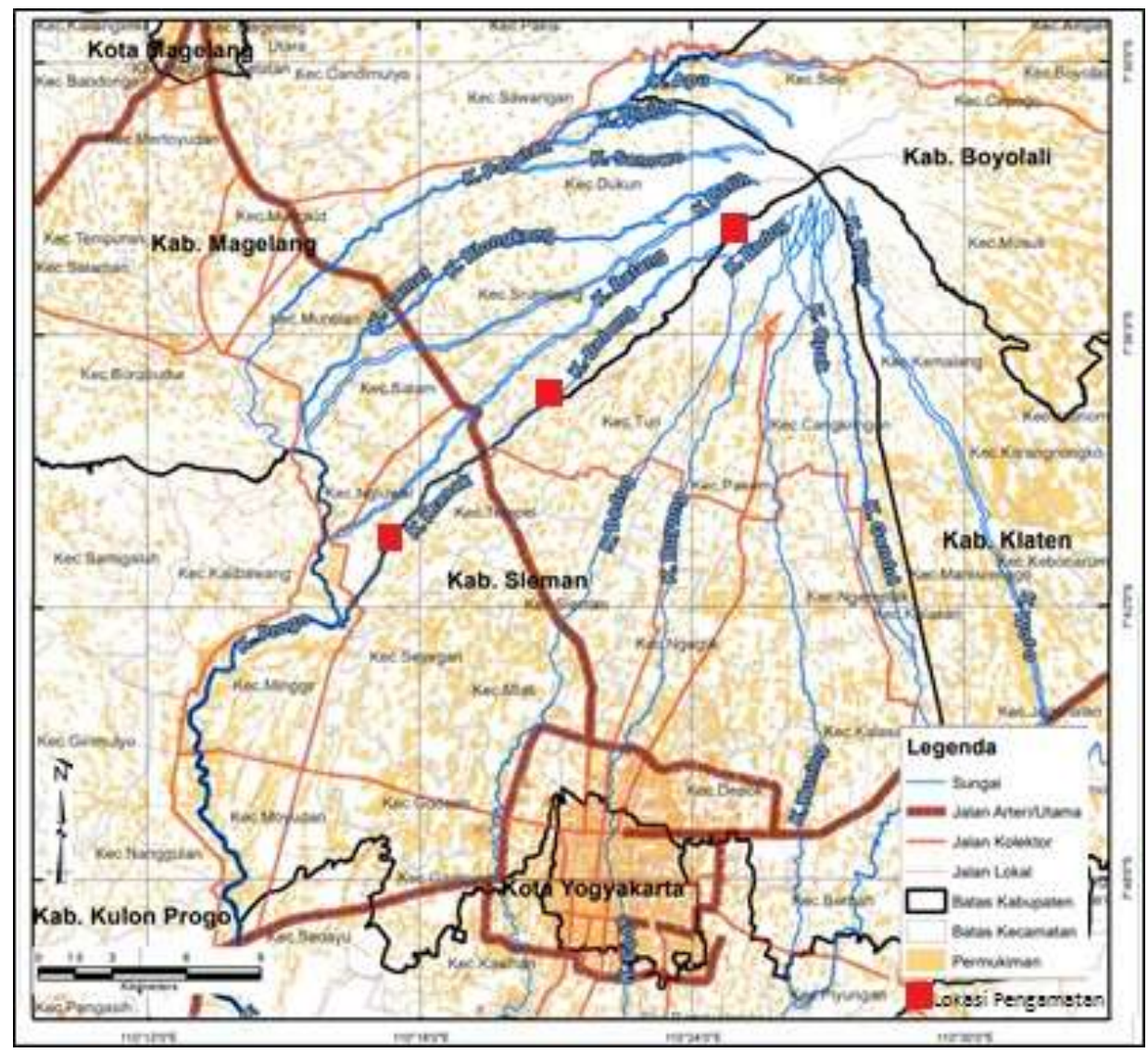

Gambar 1. Lokasi pengambilan conto (modifikasi dari BNPB, 2010).

\section{Metodologi Penelitian}

Metode penelitian yang digunakan dalam penelitian ini yaitu menggunakan conto yang dambil dari 3 lokasi di Sungai Krasak. Conto yang telah diambil kemudian dikeringkan dan dianalisis di laboratorium untuk mengetahui kandungan air. Conto pasir tersebut dianalisis menggunakan soil box dan alat resisistivititas untuk mendapatkan nilai resistivitasnya.
Berdasarkan kajian fisika, pasir tersebut kemudian dibuat model hubungan dengan nilai resistivitas. Hal yang dilakukan sebelum pengambilan conto adalah penentuan lokasi pengambilan data.

\section{Pengukuran Standar ASTM 2001}

Dalam penentuan model pengukuran yang akan digunakan menggunakan ASTM 2216, 2001. Pada penelitian ini digunakan 
conto medium asli berupa pasir kering untuk mengetahui hasil pembacaan dari nilai resistivitas Medium. Diketahui faktor $\mathrm{k}$ untuk metode $\mathrm{ASTM}=1$.

Persiapan conto dan Perhitungan dengan variabel moisture content berdasarkan ASTM 2216, 2001

1. Menyiapkan dan menghitung tempat dengan standar ASTM (Mc), g.

2. Menimbang berat conto yang telah di keringkan dengan suhu $102^{\circ}$ Celcius selama 8 jam (Mcs), g.

3. Melakukan penambahan sejumlah air dengan jumlah kelipatan $10 \mathrm{ml}$ atau 4 gr (Mcws), g.

4. Menghitung berat air, g.

$$
(\mathrm{Mw}=\text { Mcws }-\mathrm{Mcs})
$$

5. Menghitung partikel padat, g.

$$
(\mathrm{Ms}=\mathrm{Mcs}-\mathrm{Mc})
$$

6. Menghitung moisture content, \%.

$$
\mathrm{w}=(\mathrm{Mw} / \mathrm{Ms}) \times 100 \%
$$

\section{Hasil Dan Pembahasan}

Hasil Uji Hubungan Resistivitas pada Lokasi 1 Sungai Krasak Atas

Hasil uji laboratorium sampel sungai Krasak Atas dapat dilihat pada Tabel 1.

Tabel 1. Nilai Resistivitas vs Moisture Content (MC) pada sungai Krasak Atas (3 Conto).

\begin{tabular}{cccccccccccc}
\hline No & $\begin{array}{c}\text { Air } \\
(\mathbf{m l})\end{array}$ & $\boldsymbol{\%} \mathbf{M C}$ & $\begin{array}{c}\text { Resistivitas } \\
(\boldsymbol{\Omega} . \mathbf{m})\end{array}$ & $\mathbf{N o}$ & $\begin{array}{c}\text { Air } \\
(\mathbf{m l})\end{array}$ & $\boldsymbol{\%} \mathbf{M C}$ & $\begin{array}{c}\text { Resistivitas } \\
(\mathbf{\Omega} . \mathbf{m})\end{array}$ & $\mathbf{N o}$ & $\begin{array}{c}\text { Air } \\
(\mathbf{m l})\end{array}$ & $\boldsymbol{\%} \mathbf{M C}$ & $\begin{array}{c}\text { Resistivitas } \\
(\boldsymbol{\Omega} . \mathbf{m})\end{array}$ \\
\hline 1 & 3 & 2,8169 & 757,62712 & 1 & 3 & 2,098 & 1086,3057 & 1 & 3 & 2,439 & 909,23077 \\
\hline 2 & 6 & 5,5944 & 400 & 2 & 6 & 4,196 & 411,03118 & 2 & 6 & 4,878 & 365,56291 \\
\hline 3 & 9 & 8,3916 & 239,10256 & 3 & 9 & 6,294 & 242,95725 & 3 & 9 & 7,317 & 166,06061 \\
\hline 4 & 12 & 11,189 & 92,326733 & 4 & 12 & 8,392 & 201,3986 & 4 & 12 & 9,756 & 99,032882 \\
\hline 5 & 15 & 13,986 & 56,529517 & 5 & 15 & 10,49 & 138,10945 & 5 & 15 & 12,2 & 76,399395 \\
\hline 6 & 18 & 16,901 & 55,181818 & 6 & 18 & 12,68 & 112,5187 & 6 & 18 & 14,63 & 62,365591 \\
\hline 7 & 21 & 19,718 & 43,076923 & 7 & 21 & 14,89 & 93,366584 & 7 & 21 & 17,07 & 55,011933 \\
\hline 8 & 24 & 22,535 & 40,821053 & 8 & 24 & 17,14 & 78,502496 & 8 & 24 & 19,51 & 51,079914 \\
\hline 9 & 27 & 24,818 & 40,398058 & 9 & 27 & 20 & 67,687188 & 9 & 27 & 22,13 & 47,100712 \\
\hline
\end{tabular}

Pada Gambar 2 didapatkan grafik dari Electrical resistivity versus moisture content pada Sungai Krasak Atas. Hasil tersebut memperlihatkan bahwa semakin banyak kandungan air pada conto maka nilai resistivitas akan semakin kecil. Untuk kandungan moisture content pada Sungai Krasak Atas semakin sampel banyak di tambahkan air maka nilainya semakin besar. 


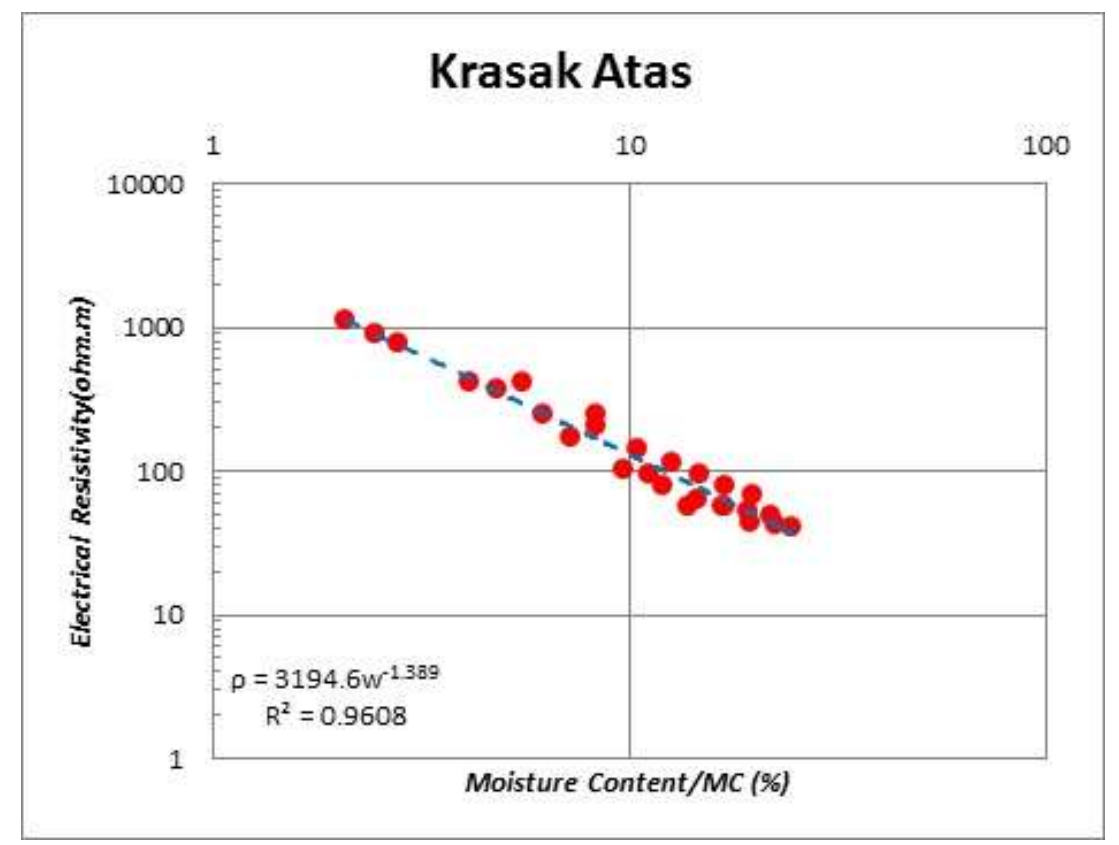

Gambar 2. Grafik Electrical resistivity versus Moisture Content pada sungai Krasak Atas.

Hasil Uji Hubungan Resistivitas Lokasi 2

Sungai Krasak Tengah

Hasil uji laboratorium sampel Sungai

Krasak Tengah dapat dilihat pada Tabel 2.

Tabel 2. Nilai Resistivitas vs Moisture Content (MC) pada sungai Krasak Tengah (3 Conto).

\begin{tabular}{cccccccccccc}
\hline No & $\begin{array}{c}\text { Air } \\
(\mathbf{m l})\end{array}$ & $\% \mathbf{M C}$ & $\begin{array}{c}\text { Resistivitas } \\
(\mathbf{\Omega} . \mathbf{m})\end{array}$ & $\mathbf{N o}$ & $\begin{array}{c}\text { Air } \\
(\mathbf{m l})\end{array}$ & $\boldsymbol{\%} \mathbf{M C}$ & $\begin{array}{c}\text { Resistivitas } \\
(\mathbf{\Omega . m})\end{array}$ & No & $\begin{array}{c}\text { Air } \\
(\mathbf{m l})\end{array}$ & $\boldsymbol{\%} \mathbf{M C}$ & $\begin{array}{c}\text { Resistivitas } \\
(\mathbf{\Omega . m})\end{array}$ \\
\hline 1 & 3 & 3,03 & 540,38462 & 1 & 3 & 3,409 & 596,93878 & 1 & 3 & 3,488 & 645,55556 \\
\hline 2 & 6 & 6,061 & 281,72589 & 2 & 6 & 6,818 & 326,77596 & 2 & 6 & 6,977 & 298,48485 \\
\hline 3 & 9 & 9,091 & 210,87866 & 3 & 9 & 10,23 & 227,51938 & 3 & 9 & 10,47 & 261,11111 \\
\hline 4 & 12 & 12,24 & 136,04061 & 4 & 12 & 13,64 & 168,35821 & 4 & 12 & 13,95 & 201,3986 \\
\hline 5 & 15 & 15,31 & 126,33929 & 5 & 15 & 17,05 & 122,19731 & 5 & 15 & 17,44 & 189,55224 \\
\hline 6 & 18 & 18,37 & 94,809689 & 6 & 18 & 20,45 & 90,367776 & 6 & 18 & 21,18 & 144,83791 \\
\hline 7 & 21 & 21,43 & 77,633478 & 7 & 21 & 24,14 & 72,740525 & 7 & 21 & 24,71 & 121,98405 \\
\hline 8 & 24 & 25,26 & 64,408867 & 8 & 24 & 27,91 & 65,706806 & 8 & 24 & 28,24 & 99,400998 \\
\hline 9 & 27 & 29,03 & 49,784017 & 9 & 27 & 32,14 & 59,124088 & 9 & 27 & 32,53 & 79,733777 \\
\hline
\end{tabular}

Pada gambar 3 menunjukan persebaran data yang relatif tidak merata dibandingkan pada Sungai Krasak Atas. hasil tersebut memperlihakan bahwa semakin banyak kandungan air berada pada conto maka nilai resistivitas akan semakin kecil. Untuk kandungan moisture content pada Sungai Krasak Tengah semakin banyak sampel di tambahkan air maka nilainya semakin besar. Nilai resitivitas pada Sungai Krasak Tengah apabila di rata-rata memiliki nilai yang relatif kecil dibandingan dengan Sungai Krasak Atas. Nilai moisture content pada Sungai Krasak tengah apabila diratarata memiliki nilai yang kecil dibandingkan dengan Sungai Krasak Atas. Hal ini bisa disebabkan karena ukuran butir pada Sungai Krasak Tengah yang semakin kecil. 


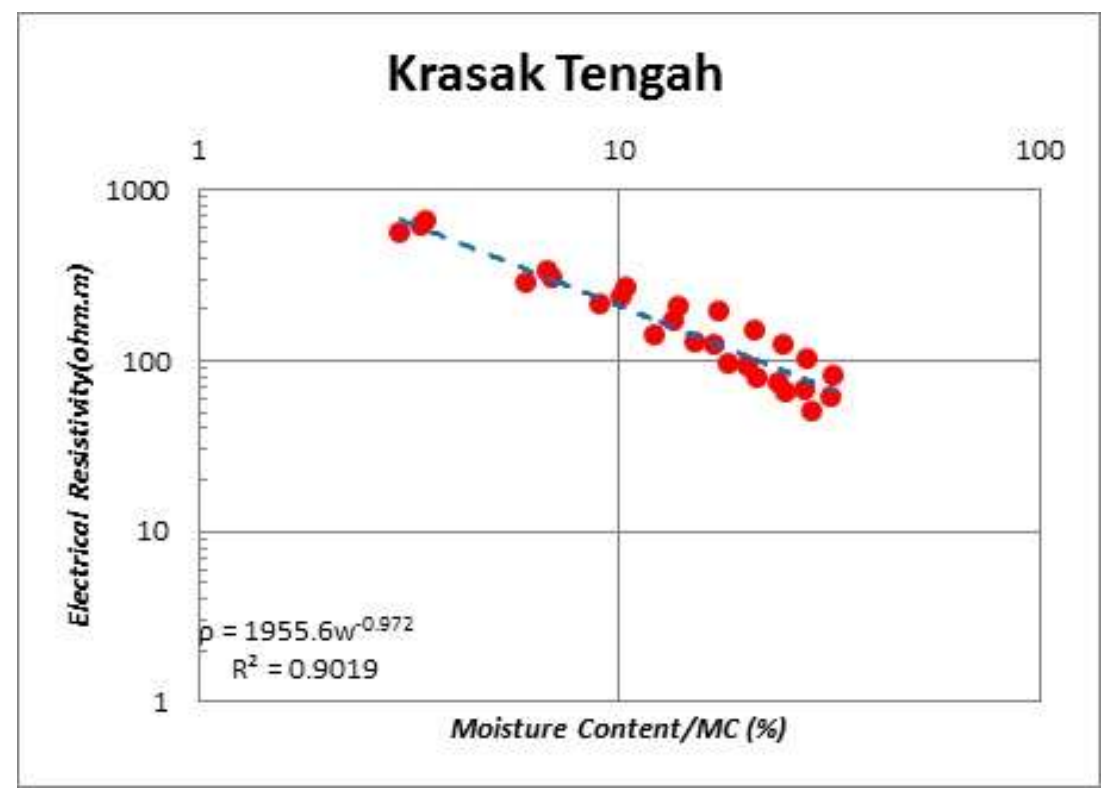

Gambar 3. Grafik Electrical resistivity versus Moisture Content pada Sungai Krasak Tengah.

Hasil Uji Hubungan Resistivitas Lokasi 3

Sungai Krasak Bawah

Hasil uji laboratorium sampel Sungai

Krasak Bawah dapat dilihat pada Tabel 3.

Tabel 3. Nilai Resistivitas vs Moisture Content (MC) pada sungai Krasak Tengah (3 Conto).

\begin{tabular}{|c|c|c|c|c|c|c|c|c|c|c|c|}
\hline No & $\begin{array}{c}\text { Air } \\
(\mathbf{m l})\end{array}$ & $\boldsymbol{\%} \mathbf{M C}$ & $\begin{array}{c}\text { Resistivitas } \\
(\boldsymbol{\Omega} . \mathbf{m})\end{array}$ & $\mathbf{N o}$ & $\begin{array}{c}\text { Air } \\
(\mathbf{m l})\end{array}$ & $\mathbf{\% M C}$ & $\begin{array}{c}\text { Resistivitas } \\
(\mathbf{\Omega} \mathbf{m})\end{array}$ & $\mathbf{N o}$ & $\begin{array}{c}\text { Air } \\
(\mathbf{m l})\end{array}$ & $\boldsymbol{\%} \mathbf{M C}$ & $\begin{array}{c}\text { Resistivitas } \\
(\mathbf{\Omega . m})\end{array}$ \\
\hline 1 & 3 & 3,03 & 540,38462 & 1 & 3 & 3,704 & 462,68657 & 1 & 3 & 3,297 & 232,83582 \\
\hline 2 & 6 & 6,061 & 281,72589 & 2 & 6 & 7,407 & 158,72383 & 2 & 6 & 6,593 & 129,05473 \\
\hline 3 & 9 & 9,091 & 210,87866 & 3 & 9 & 11,11 & 96,159601 & 3 & 9 & 9,89 & 95,760599 \\
\hline 4 & 12 & 12,24 & 136,04061 & 4 & 12 & 14,81 & 65,436409 & 4 & 12 & 13,19 & 68,229426 \\
\hline 5 & 15 & 15,31 & 126,33929 & 5 & 15 & 18,52 & 47,205589 & 5 & 15 & 16,48 & 54,209651 \\
\hline 6 & 18 & 18,37 & 94,809689 & 6 & 18 & 22,22 & 38,935108 & 6 & 18 & 19,78 & 40,898502 \\
\hline 7 & 21 & 21,43 & 77,633478 & 7 & 21 & 26,25 & 33,192517 & 7 & 21 & 23,08 & 36,454545 \\
\hline 8 & 24 & 25,26 & 64,408867 & 8 & 24 & 30,38 & 30,45614 & 8 & 24 & 26,37 & 26,552632 \\
\hline 9 & 27 & 29,03 & 49,784017 & 9 & 27 & 35,06 & 29,28 & 9 & 27 & 30 & 23,316279 \\
\hline
\end{tabular}

Pada Sungai Krasak Bawah didapatkan hubungan $\rho=1617.1 \mathrm{w}^{-1.137} \mathrm{R}^{2}=0.8565$. Pada gambar 4 menunjukan persebaran data yang relatif tidak merata dibandingkan pada Sungai Krasak tengah. Hasil tersebut memperlihatkan bahwa semakin banyak kandungan air berada pada conto maka nilai resistivitas akan semakin kecil. Untuk kandungan moisture content pada Sungai Krasak Bawah semakin banyak di tambahkan air maka nilainya semakin besar. Nilai resitivitas pada Sungai Krasak (C) 2020 Dept. of Geophysics Hasanuddin University
Bawah apabila dirata-rata memiliki nilai yang kecil dibandingan dengan Sungai Krasak Tengah dan Atas.

Nilai moisture content pada sungai Krasak Bawah apabila dirata-rata memiliki nilai yang kecil dibandingkan dengan Sungai Krasak Tegah dan Atas. Hal ini bisa disebabkan karena ukuran butir pada Sungai Krasak Bawah yang semakin kecil atau halus. 


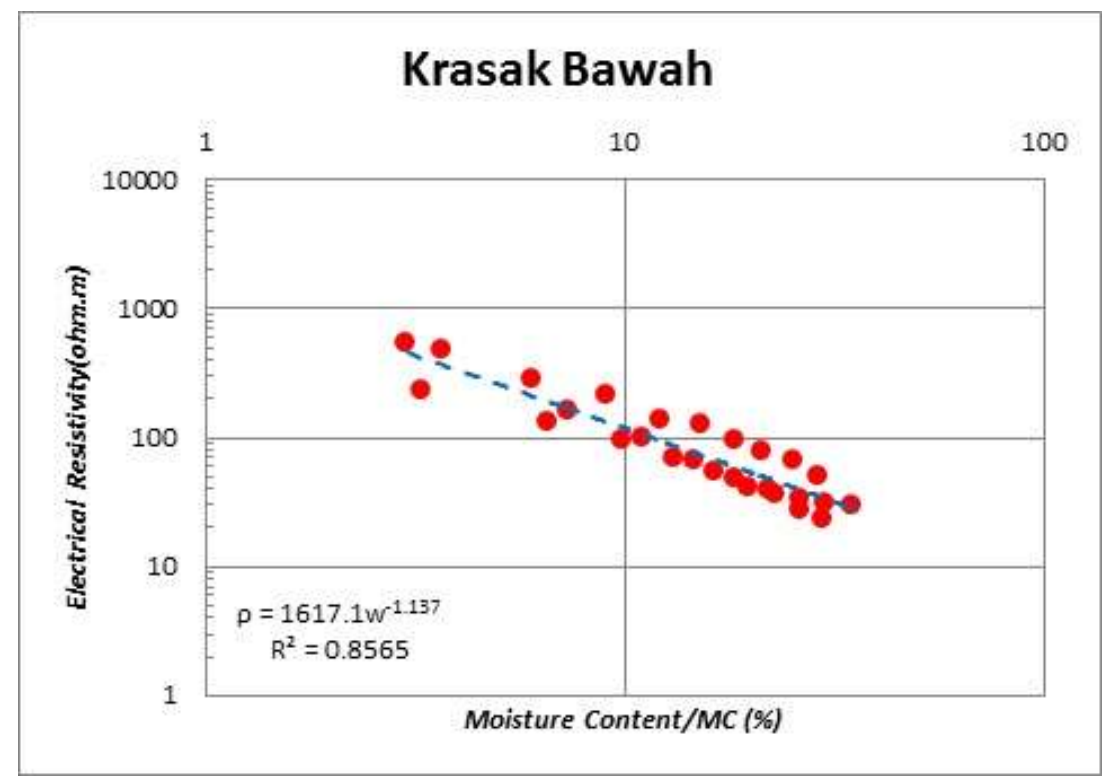

Gambar 4. Grafik Electrical resistivity versus Moisture Content pada Sungai Krasak Bawah.

Tabel 4. Hubungan Moisture Content (MC) dan resistivitas berdasarkan lokasi pengambilan data.

\begin{tabular}{clcc}
\hline No & Nama & $\boldsymbol{\rho}$ & $\mathbf{R}^{\mathbf{2}}$ \\
\hline \multirow{3}{*}{1} & $\begin{array}{l}\text { Sungai } \\
\text { Krasak } \\
\text { Atas }\end{array}$ & $3194.6 \mathrm{w}^{-1.389}$ & 0.9608 \\
& & \\
\hline \multirow{3}{*}{2} & $\begin{array}{l}\text { Sungai } \\
\text { Krasak } \\
\text { Tengah }\end{array}$ & $1955.6 \mathrm{w}^{-0.972}$ & 0.9019 \\
\hline \multirow{3}{*}{3} & $\begin{array}{l}\text { Sungai } \\
\text { Krasak } \\
\text { Bawah }\end{array}$ & $1617.1 \mathrm{w}^{-1.137}$ & 0.8565 \\
& & \\
\hline
\end{tabular}

Tabel 4 menunjukkan bahwa tingkat koefisien sebaran variasi resistivitas yang ditampilkan dengan $\mathrm{R}^{2}$ memperlihatkan nilai yang semakin kecil ke arah bawah. Dimana bawah merupakan bagian hilir, sedangkan bagian atas merupakan bagian hulu. Berdasarkan Tabel 4 dapat dijelaskan bahwa Sungai Krasak semakin jauh dari hulu maka variasi nilai resistivitas semakin beragam akibat semakin jauh dari sumber. Sedangkan di bagian hulu memiliki variasi nilai resistivitas yang lebih seragam hal ini dikarenakan lebih dekat dengan batuan sumbernya.

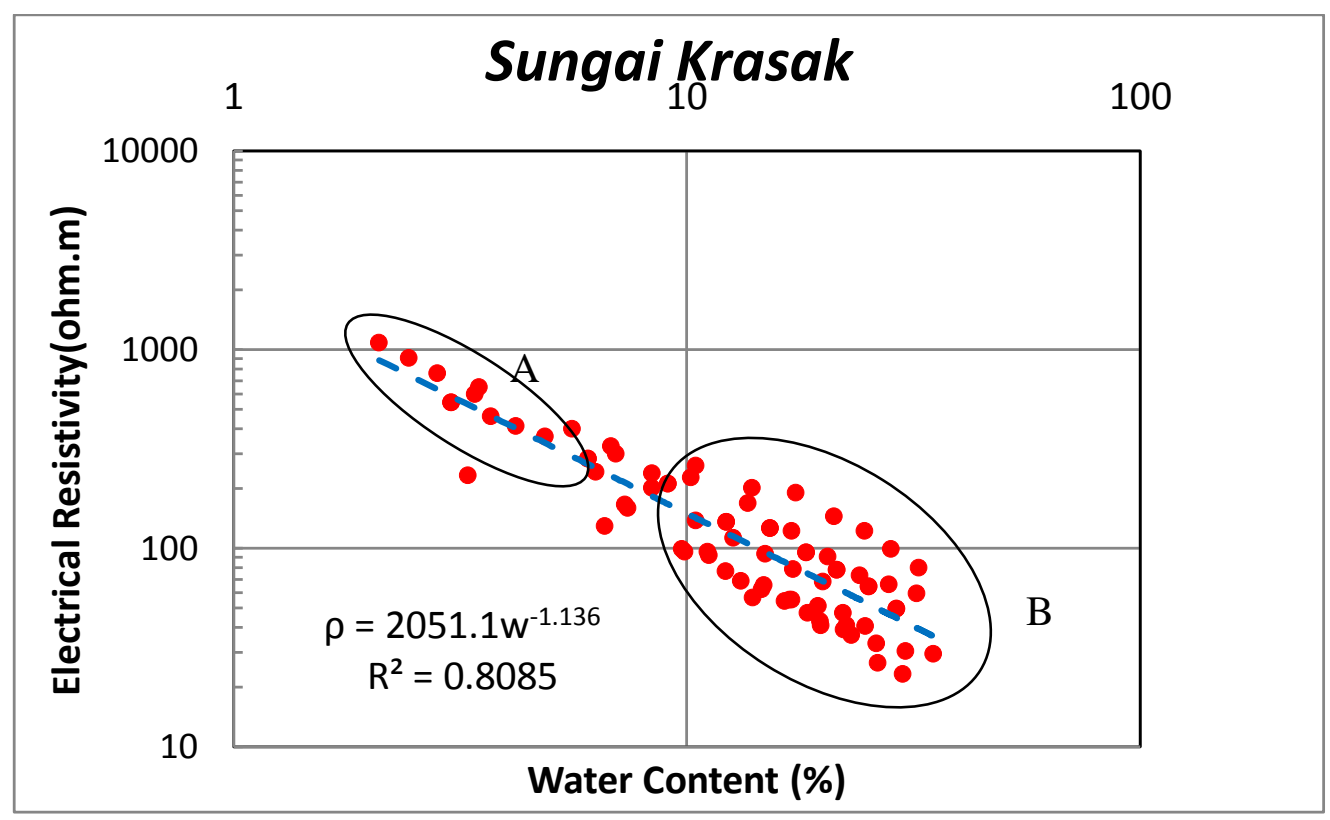

Gambar 5. Hubungan Nilai Moisture Content pada endapan pasir lepas Sungai Krasak. 
Gambar 5 merupakan hubungan antara nilai resistivitas terhadap moisture content gabungan pada Sungai Krasak Atas, Tengah dan Bawah. Berdasarkan grafik crossplot ditunjukan pada nilai moisture content yang tinggi (ditunjukkan A) lebih besar dari $7 \%$ ini menunjukan variasi nilai resistivitas yang tidak merata. Sedangkan pada nilai tingkat moisture content rendah (ditunjukkan B) nilai resistivitas cenderung stabil sesuai dengan pola trendline.

\section{Kesimpulan}

Dari penelitian didapat kesimpulan:

1. Nilai resistivitas endapan pasir lepas di Sungai Krasak berkisar antara 23,31 $\Omega \mathrm{m}$ - 1086,302 $\Omega$ m.

2. Semakin jauh dari batuan sumber menunjukan sebaran variasi nilai resistivias lebih variatif, pada Sungai Krasak Atas (hulu).

3. Semakin tinggi nilai moisture content maka nilai resistivitas semakin rendah.

\section{Saran}

Akusisi data geolistrik perlu dilakukan dan melakukan uji inversi dengan menggunakan batasan nilai $\rho$ dari persamaan.

\section{Ucapan Terimakasih}

Ucapan terimakasih diberikan kepada LPPM UPN Veteran Yogyakarta yang telah memberikan hibah penelitian dasar.

\section{Daftar Pustaka}

ASTM Standar 2216, 2001. Field Measurement of Soil Resistivity Using the Wenner Four-Electrode Method, West Conshohocken, PA, www.astm.org

BNPB. 2010. Peta Aliran Sungai Utama di Wilayah Gunung DIY.

Matsui, T., Park, G. Y., Park, K. M., and Matsuura, S. 2000. Relationship
Between Electrical Resistivity and Physical Properties of Rocks. International Society for Rock Mechanics and Rock Engineering, Melbourne.

Rahman, T., Lebedev, M., Zhang, Y., Barifeani, A., and Iglauer, S. 2016. Influence of rock microstucture on its electrical properties: an analysis using $x$-ray microcomputed tomography. 13th International Conference on Greenhouse Gas Control Tecnologies (GHGT-13), p 14-18, Lausanne.

van Bemmelen, R.W. 1949. The Geology of Indonesia Vol. IA. Government Printing Office, The Hague. 